\title{
PENGARUH TINGKAT PENDIDIKAN, PENGALAMAN KERJA, ETIKA PROFESI, DAN INDEPENDENSI AUDITOR TERHADAP KUALITAS AUDIT \\ (Studi Empiris Pada Kantor Akuntan Publik di Jakarta Barat)
}

\author{
Galih Chandra Kirana, SE., M.Ak \\ chandra.galih13@gmail.com
}

Universitas Satya Negara Indonesia

\begin{abstract}
ABSTRAK
Tujuan penelitian ini adalah untuk mengetahui pengaruh tingkat pendidikan, pengalaman kerja, etika profesi, dan independensi auditor terhadap kualitas audit. Populasi dalam penelitian ini adalah auditor yang bekerja di Kantor Akuntan Publik di wilayah Jakarta Barat yang terdaftar di Direktorat Institut Akuntan Publik Indonesia (IAPI). Sampel yang digunakan pada penelitian ini sebanyak 58 responden dari 16 Kantor Akuntan Publik. Data penelitian ini adalah data primer yang diperoleh melalui penyebaran kuesioner. Teknik pengambilan sampel menggunakan purposive sampling, sedangkan metode pengolahan data yang digunakan peneliti adalah analisis linear berganda dengan bantuan SPSS versi 21. Hasil penelitian ini menunjukkan bahwa tingkat pendidikan dan etika profesi secara parsial berpengaruh terhadap kualitas audit, sedangkan pengalaman kerja dan independensi auditor tidak berpengaruh terhadap kualitas audit.

Kata kunci: Tingkat Pendidikan, Pengalaman Kerja, Etika Profesi, Independensi Auditor, Kualitas Audit.

\section{PENDAHULUAN}

Seorang auditor dalam melaksanakan tugas auditnya harus berpedoman pada standar audit yang ditetapkan oleh Institut Akuntan Publik Indonesia (IAPI), yakni standar umum, standar pekerjaan lapangan, dan standar pelaporan. Dimana standar umum adalah merupakan cerminan kualitas pribadi yang harus dimiliki oleh seorang auditor yang mengharuskan auditor untuk memiliki keahlian dan pelatihan teknis yang cukup dalam melaksanakan prosedur audit. Sedangkan standar pekerjaan lapangan dan standar pelaporan mengatur auditor dalam hal pengumpulan data dan kegiatan lainnya yang dilaksanakan selama melakukan audit serta mewajibkan auditor untuk menyusun suatu laporan atas laporan keuangan yang diaudit secara keseluruhan.
\end{abstract}

\section{Tujuan Penelitian}

Berdasarkan perumusan masalah yang telah diuraikan diatas, maka tujuan yang ingin dicapai dalam penelitian ini Untuk mengetahui pengaruh tingkat pendidikan, pengalaman kerja, etika profesi, independensi auditor terhadap kualitas audit.

\section{LANDASAN TEORI}

Definisi Audit

Menurut Mulyadi (2016:9) pengertian auditing adalah: 
Suatu proses sistematik untuk memperoleh dan mengevaluasi bukti secara objektif mengenai pernyataan-pernyataan tentang kegiatan dan kejadian ekonomi, dengan tujuan untuk menetapkan tingkat kesesuaian antara pernyataan-pernyataan tersebut dengan kriteria yang telah ditetapkan, serta penyampaian hasil-hasilnya kepada pemakai yang berkepentingan.

\section{Standar Audit}

Mulyadi (2016:16) mendefinisikan "Standar auditing adalah suatu ukuran pelaksanaan tindakan yang merupakan pedoman umum bagi auditor dalam melaksanakan audit”.

Dengan adanya standar yang telah ditetapkan, diharapkan bahwa dalam pelaksanaan pemeriksaan para auditor harus sesuai dengan standar-standar yang berlaku umum di Indonesia. Sehingga hasil pemeriksaannya dapat memberikan keyakinan yang penuh oleh para pengguna jasa auditor baik pihak internal maupun eksternal.

\section{Prosedur Audit}

Mulyadi (2017:86) mendefinisikan prosedur audit adalah "instruksi rincian untuk mengumpulkan tipe bukti audit tertentu yang harus diperoleh pada saat tertentu dalam audit”.

\section{Tingkat Pendidikan}

Berdasarkan Undang-Undang No. 20 Tahun 2003 tentang Sistem Pendidikan Nasional, pendidikan adalah usaha sadar dan terencana untuk mewujudkan suasana belajar dan proses pembelajaran agar peserta didik secara aktif mengembangkan potensi dirinya untuk memiliki kekuatan spiritual keagamaan, pengendalian diri, kepribadian, kecerdasan, akhlak mulia, serta keterampilan yang diperlukan dirinya, masyarakat, bangsa dan negara.

\section{Pengalaman Kerja}

Knoers dan Haditono (2010) dalam Singgih dan Bawono (2018) mendefinisikan pengalaman merupakan suatu proses pembelajaran dan penambahan perkembangan potensi bertingkah laku baik dari pendidikan formal maupun non formal atau bisa juga diartikan sebagai suatu proses yang membawa seseorang kepada suatu pola tingkah laku yang lebih tinggi.

\section{Etika Profesi}

Sukrisno dan Cenik (2016:13) mendefinisikan etika adalah: Cabang ilmu yang membahas tentang perilaku manusia, mengenai apa yang baik dan apa yang tidak baik dalam konteks hubungan manusia dan Tuhan, manusia dengan manusia lain dan manusia dengan alam.

\section{Independensi Auditor}

Menurut Sukrisno Agoes (2017: L19) independensi adalah "sikap yang diharapkan dari seorang akuntan publik untuk tidak mempunyai kepentingan pribadi dalam pelaksanaan tugasnya, yang bertentangan dengan prinsip integritas dan objektivitas". 


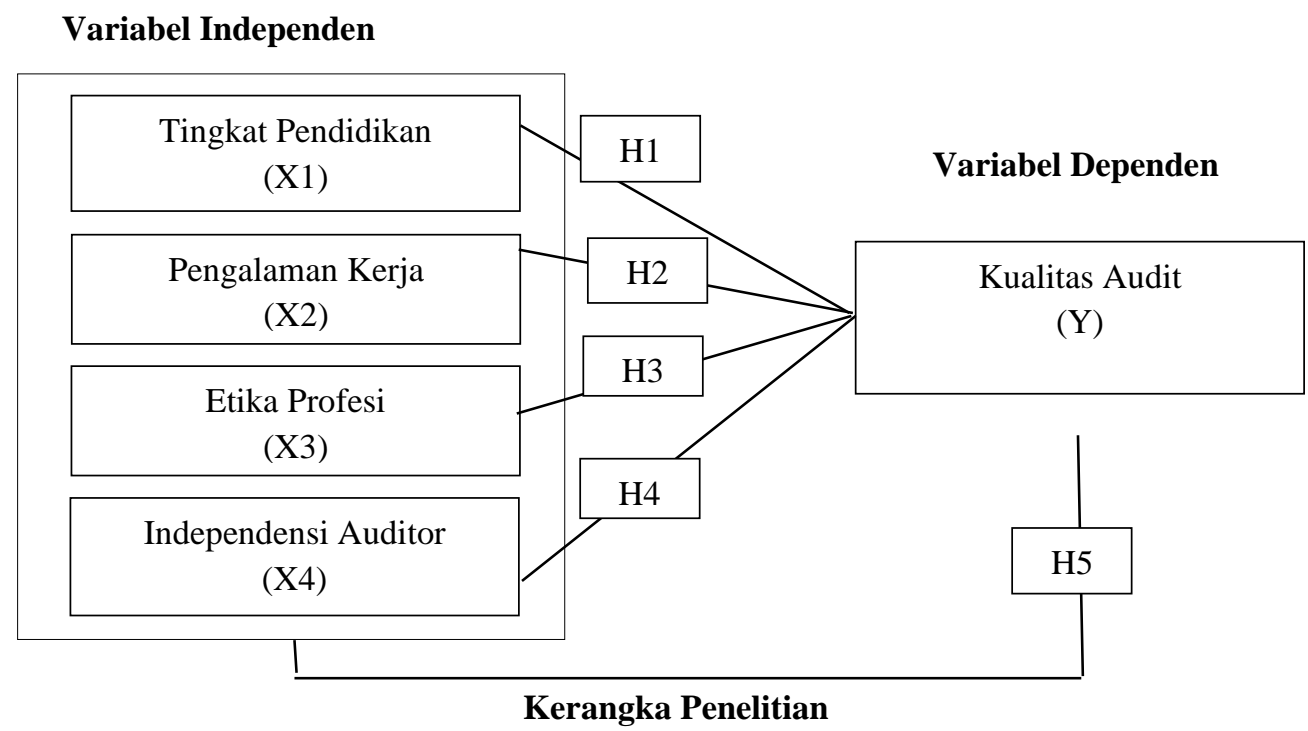

\section{METODOLOGI PENELITIAN}

\section{Waktu Penelitian}

Penelitian ini dilaksanakan pada bulan April 2021 sampai dengan bulan Juli 2021

\section{Tempat Penelitian}

Dalam penelitian ini, peneliti melakukan penelitian di Kantor Akuntan Publik (KAP) yang berada di wilayah Jakarta Barat, yang terdaftar dalam Institut Akuntan Publik Indonesia (IAPI), Directory tahun 2020.

\section{Metode Pengumpulan Data}

Ada dua cara metode pengumpulan data yang digunakan dalam penelitian ini yaitu :

1. Penelitian kepustakaan (Library research)

2. Penelitian lapangan (Field research)

\section{Jenis Data}

Dalam penelitian ini peneliti menggunakan data primer. Data primer adalah data yang diperoleh langsung dari objek yang diteliti yang digunakan untuk mengukur variabel independen (Tingkat Pendidikan, Pengalaman Kerja, Etika Profesi, dan Independesi Auditor) serta variabel dependen (Kualitas Audit) yang diambil dari individu atau perseorangan, seperti hasil pengujian kuesioner.

\section{Populasi}

Dalam penelitian ini, populasi yang diambil yaitu auditor yang bekerja di Kantor Akuntan Publik (KAP) yang berada di wilayah Jakarta Barat sesuai dengan Directory Kantor Akuntan Publik yang dikeluarkan oleh IAPI pada tahun 2020 . 


\section{Sampel}

Sampel dalam penelitian ini diambil dengan menggunakan metode Purposive Sampling yaitu merupakan teknik pengambilan sampel yang didasarkan atas pertimbangan-pertimbangan tertentu dari peneliti. Pemberian kriteria ini bertujuan agar pernyataan yang terdapat dalam kuesioner penelitian diisi oleh responden yang tepat.

\section{Statistik Deskriptif}

Metode statistik deskriptif merupakan pencatatan data yang disertakan dengan kalimat, kata maupun gambar untuk memberikan gambaran mengenai variabel yang diteliti, namun tidak digunakan untuk membuat kesimpulan.

\section{Analisis Instrumen Penelitian}

Analisis instrumen penelitian dilakukan untuk menguji apakah instrumen yang digunakan memenuhi syarat-syarat sebagai alat ukur yang baik atau tidak apabila instrumen penelitian tersebut memenuhi beberapa sifat valid (tepat) dan reliabel (handal).

\section{ANALISIS HASIL DAN PEMBAHASAN}

Kuesioner yang disebar sebanyak 80 kuesioner, namun kuesioner yang kembali sebanyak 58 kuesioner, tidak kembali 22 kuesioner. Kuesioner yang tidak kembali disebabkan karena wakut penelitian yang diambil oleh peneliti bertepatan dengan waktu penugasan auditor, sehingga ketika menyebar kuesioner para auditor sedang tidak berada dikantor akuntan publik tempat mereka bekerja melainkan di tempat klien yang mereka audit. Oleh karena itu, para auditor tidak sempat untuk mengisi kuesioner penelitian. diolah.

Dari 80 kuesioner yang disebar, sebanyak 58 kuesioner yang layak untuk

\section{Uji Validitas}

Tabel $r$ untuk df = 51 sampai 54

\begin{tabular}{|c|c|c|c|c|c|}
\hline \multirow{3}{*}{ df = n-k-1 } & \multicolumn{5}{|c|}{ Tingkat Signifikansi untuk Uji Satu Sisi } \\
\cline { 2 - 6 } & $\mathbf{0 , 0 5}$ & $\mathbf{0 , 0 2 5}$ & $\mathbf{0 , 0 1}$ & $\mathbf{0 , 0 0 5}$ & $\mathbf{0 , 0 0 0 5}$ \\
\cline { 2 - 6 } & \multicolumn{4}{|c|}{ Tingkat Signifikansi untuk Uji Dua Sisi } \\
\cline { 2 - 6 } & $\mathbf{0 , 1}$ & $\mathbf{0 , 0 5}$ & $\mathbf{0 , 0 2}$ & $\mathbf{0 , 0 1}$ & $\mathbf{0 , 0 0 1}$ \\
\hline $\mathbf{5 1}$ & 0,2284 & 0,2706 & 0,3188 & 0,3509 & 0,4393 \\
\hline $\mathbf{5 2}$ & 0,2262 & 0,2681 & 0,3158 & 0,3477 & 0,4354 \\
\hline $\mathbf{5 3}$ & 0,2241 & 0,2656 & 0,3129 & 0,3445 & 0,4317 \\
\hline $\mathbf{5 4}$ & 0,2221 & $\mathbf{0 , 2 6 3 2}$ & 0,3102 & 0,3415 & 0,4280 \\
\hline
\end{tabular}

Berdasarkan tabel dapat dilihat nilai $r$ tabel sebesar 0,2656. Jika $r$ hitung (per item) $>\mathrm{r}$ tabel berarti pernyataan tersebut dikatakan valid. Hasil uji validitas untuk $r$ hitung per item (butir pernyataan) dapat dilihat dari hasil output SPSS pada kolom Corrected Item-Total Correlation seperti yang disajikan sebagai berikut : 


\section{Uji Validitas Variabel Pengalaman Kerja $\left(\mathbf{X}_{2}\right)$}

Item-Total Statistics

\begin{tabular}{|l|r|r|r|r|r|}
\hline & $\begin{array}{c}\text { Scale Mean } \\
\text { if Item } \\
\text { Deleted }\end{array}$ & $\begin{array}{c}\text { Scale } \\
\text { Variance if } \\
\text { Item } \\
\text { Deleted }\end{array}$ & $\begin{array}{r}\text { Corrected } \\
\text { Item-Total } \\
\text { Correlatio } \\
\mathrm{n}\end{array}$ & $\begin{array}{c}\text { Squared } \\
\text { Multiple } \\
\text { Correlatio } \\
\mathrm{n}\end{array}$ & $\begin{array}{c}\text { Cronbach's } \\
\text { Alpha if } \\
\text { Item } \\
\text { Deleted }\end{array}$ \\
\hline $\begin{array}{l}\text { Pengalaman } \\
\text { Kerja } \\
\begin{array}{l}\text { Pengalaman } \\
\text { Kerja } \\
\text { Pengalaman } \\
\text { Kerja }\end{array}\end{array}$ & 8,78 & 1,019 &, 528 &, 298 &, 776 \\
\hline
\end{tabular}

Sumber: Data Output SPSS 21.0

Berdasarkan tabel hasil output SPSS uji validitas variabel Pengalaman Kerja (X2) di atas, menunjukkan bahwa semua item, yaitu butir pernyataan 1 - 3 dinyatakan valid dan tidak ada butir pernyataan yang dihilangkan karena secara keseluruhan hasil dari nilai koefisien korelasi yaitu $r$ hitung (per item) pada kolom Corrected Item-Total Correlation yang dihasilkan nilainya lebih besar dari nilai $\mathrm{r}$ tabel $\left(\mathrm{r}_{\text {tabel }}=0,2656\right)$.

\section{Uji Validitas Variabel Etika Profesi $\left(\mathbf{X}_{3}\right)$}

Item-Total Statistics

\begin{tabular}{|l|r|r|r|r|r|}
\hline & $\begin{array}{c}\text { Scale } \\
\text { Mean if } \\
\text { Item } \\
\text { Deleted }\end{array}$ & $\begin{array}{c}\text { Scale } \\
\text { Variance } \\
\text { if Item } \\
\text { Deleted }\end{array}$ & $\begin{array}{c}\text { Corrected } \\
\text { Item-Total } \\
\text { Correlation }\end{array}$ & $\begin{array}{c}\text { Squared } \\
\text { Multiple } \\
\text { Correlation }\end{array}$ & $\begin{array}{c}\text { Cronbach's } \\
\text { Alpha if Item } \\
\text { Deleted }\end{array}$ \\
\hline Etika Profesi & 29,97 & 10,876 &, 882 &, 821 &, 880 \\
Etika Profesi & 29,97 & 10,630 &, 845 &, 836 &, 882 \\
Etika Profesi & 30,02 & 10,859 &, 729 &, 682 &, 892 \\
Etika Profesi & 29,86 & 12,191 &, 563 &, 478 &, 905 \\
Etika Profesi & 29,86 & 11,068 &, 754 &, 600 &, 890 \\
Etika Profesi & 29,86 & 11,209 &, 713 &, 538 &, 893 \\
Etika Profesi & 29,81 & 10,893 &, 701 &, 561 &, 895 \\
Etika Profesi & 30,10 & 11,077 &, 519 &, 354 &, 917 \\
\hline
\end{tabular}

Sumber: Data Output SPSS 21.0

Berdasarkan table, hasil output SPSS uji validitas variabel Etika Profesi (X3) di atas, menunjukkan bahwa semua item, yaitu butir pernyataan 1 - 8 dinyatakan valid dan tidak ada butir pernyataan yang dihilangkan karena secara keseluruhan hasil dari nilai koefisien korelasi yaitu $r$ hitung (per item) pada kolom Corrected Item-Total Correlation yang dihasilkan nilainya lebih besar dari nilai $\mathrm{r}$ tabel $\left(\mathrm{r}_{\text {tabel }}=0,2656\right)$. 


\section{Uji Validitas Variabel Independensi Auditor $\left(\mathbf{X}_{4}\right)$}

Item-Total Statistics

\begin{tabular}{|l|r|r|r|r|r|}
\hline & $\begin{array}{c}\text { Scale } \\
\text { Mean if } \\
\text { Item } \\
\text { Deleted }\end{array}$ & $\begin{array}{c}\text { Scale } \\
\text { Variance } \\
\text { if Item } \\
\text { Deleted }\end{array}$ & $\begin{array}{c}\text { Corrected } \\
\text { Item - } \\
\text { Total } \\
\text { Correlation }\end{array}$ & $\begin{array}{c}\text { Squared } \\
\text { Multiple } \\
\text { Correlation }\end{array}$ & $\begin{array}{c}\text { Cronbach's } \\
\text { Alpha if } \\
\text { Item } \\
\text { Deleted }\end{array}$ \\
\hline Independensi Auditor & 15,53 & 5,551 &, 378 &, 169 &, 731 \\
Independensi Auditor & 15,22 & 5,510 &, 634 &, 414 &, 647 \\
Independensi Auditor & 15,05 & 5,945 &, 421 &, 222 &, 711 \\
Independensi Auditor & 15,52 & 4,465 &, 569 &, 388 &, 656 \\
Independensi Auditor & 15,36 & 5,147 &, 524 &, 314 &, 672 \\
\hline
\end{tabular}

Sumber: Data Output SPSS 21.0

Berdasarkan table, hasil output SPSS uji validitas variabel Independensi Auditor (X4) di atas, menunjukkan bahwa semua item, yaitu butir pernyataan 1 - 5 dinyatakan valid dan tidak ada butir pernyataan yang dihilangkan karena secara keseluruhan hasil dari nilai koefisien korelasi yaitu $r$ hitung (per item) pada kolom Corrected Item-Total Correlation yang dihasilkan nilainya lebih besar dari nilai $r$ tabel $\left(\mathrm{r}_{\text {tabel }}=0,2656\right)$.

\section{Uji Validitas Variabel Kualitas Audit (Y)}

Item-Total Statistics

\begin{tabular}{|l|r|r|r|r|r|}
\hline & $\begin{array}{c}\text { Scale } \\
\text { Mean if } \\
\text { Item } \\
\text { Deleted }\end{array}$ & $\begin{array}{c}\text { Scale } \\
\text { Variance if } \\
\text { Item } \\
\text { Deleted }\end{array}$ & $\begin{array}{c}\text { Corrected } \\
\text { Item-Total } \\
\text { Correlation }\end{array}$ & $\begin{array}{c}\text { Squared } \\
\text { Multiple } \\
\text { Correlation }\end{array}$ & $\begin{array}{c}\text { Cronbach's } \\
\text { Alpha if } \\
\text { Item } \\
\text { Deleted }\end{array}$ \\
\hline Kualitas Audit & 17,50 & 3,272 &, 538 &, 398 &, 760 \\
Kualitas Audit & 17,48 & 3,201 &, 476 &, 309 &, 780 \\
Kualitas Audit & 17,50 & 3,096 &, 592 &, 380 &, 743 \\
Kualitas Audit & 17,26 & 2,967 &, 599 &, 529 &, 740 \\
Kualitas Audit & 17,36 & 2,832 &, 642 &, 525 &, 725 \\
\hline
\end{tabular}

Sumber: Data Output SPSS 21.0

Berdasarkan table, hasil output SPSS uji validitas variabel Kualitas Audit (Y) di atas, menunjukkan bahwa semua item, yaitu butir pernyataan 1 - 5 dinyatakan valid dan tidak ada butir pernyataan yang dihilangkan karena secara keseluruhan hasil dari nilai koefisien korelasi yaitu $\mathrm{r}$ hitung (per item) pada kolom Corrected Item-Total Correlation yang dihasilkan nilainya lebih besar dari nilai $r$ tabel $\left(\mathrm{r}_{\text {tabel }}=0,2656\right)$. 


\section{Uji Reliabilitas}

\section{Uji Reliabilitas Variabel Tingkat Pendidikan $\left(\mathbf{X}_{1}\right)$}

\section{Reliability Statistics}

\begin{tabular}{|r|c|c|}
\hline $\begin{array}{c}\text { Cronbach's } \\
\text { Alpha }\end{array}$ & $\begin{array}{c}\text { Cronbach's } \\
\text { Alpha Based } \\
\text { on } \\
\text { Standardized } \\
\text { Items }\end{array}$ & Items \\
\hline, 752 &, 750 & \\
\hline
\end{tabular}

Sumber: Data Output SPSS 21.0

Berdasarkan table di atas, menunjukkan Cronbach's Alpha 0,752 > 0,70. Hal ini dapat disimpulkan bahwa pernyataan-pernyataan dalam variabel tingkat pendidikan adalah reliable, yang berarti bahwa hasil pengukuran tingkat pendidikan adalah konsisten.

\section{Uji Reliabilitas Variabel Pengalaman Kerja $\left(\mathbf{X}_{2}\right)$}

Hasil Uji Reliabilitas Pengalaman Kerja

Reliability Statistics

\begin{tabular}{|r|r|r|}
\hline $\begin{array}{c}\text { Cronbach's } \\
\text { Alpha }\end{array}$ & $\begin{array}{c}\text { Cronbach's } \\
\text { Alpha Based } \\
\text { on } \\
\text { Standardized } \\
\text { Items }\end{array}$ & $\begin{array}{c}\text { Items of } \\
\end{array}$ \\
\hline, 767 &, 771 & 3 \\
\hline
\end{tabular}

Sumber: Data Output SPSS 21.0

Berdasarkan tabel di atas, menunjukkan Cronbach's Alpha 0,767 > 0,70. Hal ini dapat disimpulkan bahwa pernyataan-pernyataan dalam variabel pengalaman kerja adalah reliable, yang berarti bahwa hasil pengukuran pengalaman kerja adalah konsisten.

\section{Uji Reliabilitas Variabel Etika Profesi $\left(\mathbf{X}_{3}\right)$}

\section{Reliability Statistics}

\begin{tabular}{|r|c|c|}
\hline $\begin{array}{c}\text { Cronbach's } \\
\text { Alpha }\end{array}$ & $\begin{array}{c}\text { Cronbach's } \\
\text { Alpha Based } \\
\text { on } \\
\text { Standardized } \\
\text { Items }\end{array}$ & Items \\
\hline, 906 &, 912 & 8 \\
\hline
\end{tabular}

Sumber: Data Output SPSS 21.0

Berdasarkan tabel di atas, menunjukkan Cronbach's Alpha 0,906 > 0,70. Hal ini dapat disimpulkan bahwa pernyataan-pernyataan dalam variabel etika profesi adalah reliable, yang berarti bahwa hasil pengukuran etika profesi adalah konsisten. 


\section{Uji Reliabilitas Variabel Independensi Auditor ( $\left.\mathbf{X}_{3}\right)$}

\section{Reliability Statistics}

\begin{tabular}{|r|c|c|}
\hline $\begin{array}{c}\text { Cronbach's } \\
\text { Alpha }\end{array}$ & $\begin{array}{c}\text { Cronbach's } \\
\text { Alpha Based } \\
\text { on } \\
\text { Standardized } \\
\text { Items }\end{array}$ & $\begin{array}{c}\text { N of } \\
\text { Items }\end{array}$ \\
\hline, 731 &, 742 & 5 \\
\hline
\end{tabular}

Sumber: Data Output SPSS 21.0

Berdasarkan tabel di atas, menunjukkan Cronbach's Alpha 0,731 >0,70. Hal ini dapat disimpulkan bahwa pernyataan-pernyataan dalam variabel independensi auditor adalah reliable, yang berarti bahwa hasil pengukuran independensi auditor adalah konsisten.

\section{Uji Reliabilitas Variabel Kualitas Audit (Y)}

Reliability Statistics

\begin{tabular}{|r|c|c|}
\hline $\begin{array}{c}\text { Cronbach's } \\
\text { Alpha }\end{array}$ & $\begin{array}{c}\text { Cronbach's } \\
\text { Alpha Based } \\
\text { on } \\
\text { Standardized } \\
\text { Items }\end{array}$ & N of \\
& $\begin{array}{c}\text { Items } \\
\text {,790 }\end{array}$ \\
\hline
\end{tabular}

Sumber: Data Output SPSS 21.0

Berdasarkan tabel di atas, menunjukkan Cronbach's Alpha 0,790>0,70. Hal ini dapat disimpulkan bahwa pernyataan-pernyataan dalam variabel kualitas audit adalah reliable, yang berarti bahwa hasil pengukuran kualitas audit adalah konsisten.

\section{Uji Normalitas}

Hasil Uji Normalitas

One-Sample Kolmogorov-Smirnov Test

\begin{tabular}{|ll|r|}
\hline & & Unstandardized Residual \\
\hline $\mathrm{N}$ & & 58 \\
Normal Parameters & &, 0000000 \\
& Mean & Std. Deviation \\
Most Extreme & Absolute &, 80808713 \\
Differences & Positive &, 098 \\
& Negative &, 098 \\
Kolmogorov-Smirnov Z & &,- 069 \\
Asymp. Sig. (2-tailed) & &, 749 \\
\hline
\end{tabular}

a. Test distribution is Normal.

b. Calculated from data.

\section{Sumber: Data Output SPSS 21.0}

Berdasarkan table output SPSS hasil uji normalitas dengan One Sample Kolmogorov dapat diketahui bahwa data dalam penelitian berdistribusi normal. Hal ini dapat dilihat dari Asymp Sig (2-tailed) nilai Sig $=0,629>0,05$. Maka dapat disimpulkan bahwa Ha diterima , artinya data residual berdistribusi normal. 
Berdasarkan hasil output spss data normalitas juga dapat dilihat melalui Gambar di bawah ini :

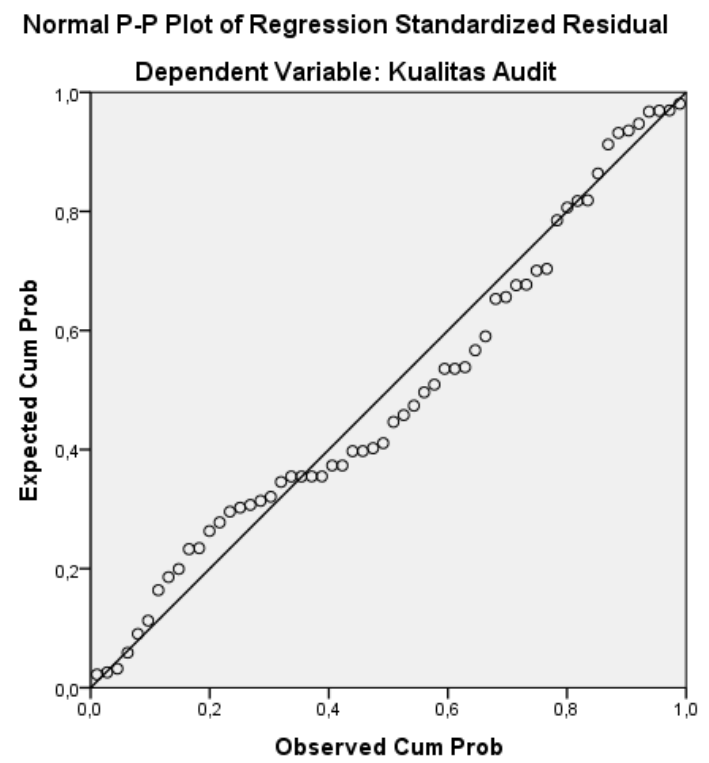

Hasil Uji Normalitas

Sumber: Data Output SPSS 21.0

\section{Uji Multikolonieritas}

Berdasarkan Tabel output SPSS hasil uji multikolonieritas di atas menunjukkan besarnya nilai Tolerance dan Variant Inflation Factor (VIF) untuk masing-masing variabel independen yaitu nilai Tolerance $>0,10$ dan nilai VIF < 10 sehingga dapat disimpulkan bahwa antara variabel independensi tidak terjadi multikolonieritas.

\section{Uji Heteroskedastisitas}

Hasil Uji Heteroskedastisitas

Sumber: Data Output SPSS 21.0

\section{Coefficients $^{\mathrm{a}}$}

\begin{tabular}{|c|c|c|c|c|c|c|}
\hline \multirow{2}{*}{\multicolumn{2}{|c|}{ Model }} & \multicolumn{2}{|c|}{$\begin{array}{l}\text { Unstandardized } \\
\text { Coefficients }\end{array}$} & \multirow{2}{*}{$\begin{array}{c}\begin{array}{c}\text { Standardize } \\
\mathrm{d} \\
\text { Coefficients }\end{array} \\
\text { Beta }\end{array}$} & \multirow[t]{2}{*}{$\mathrm{t}$} & \multirow[t]{2}{*}{ Sig. } \\
\hline & & $\mathrm{B}$ & $\begin{array}{l}\text { Std. } \\
\text { Error }\end{array}$ & & & \\
\hline \multirow{5}{*}{1} & (Constant) & 1,587 & ,966 & & 1,642 & , 106 \\
\hline & Tingkat Pendidikan &, 083 & 081 & , 194 & 1,019 & ,313 \\
\hline & Pengalaman Kerja &, 118 & 093 & ,224 & 1,279 & ,206 \\
\hline & Etika Profesi &,- 099 & 042 &,- 459 & $-2,375$ & 021 \\
\hline & $\begin{array}{l}\text { Independensi } \\
\text { Auditor }\end{array}$ & ,005 &, 051 &, 014 & ,092 & ,927 \\
\hline
\end{tabular}

a. Dependent Variable: ABS_RES

Berdasarkan tabel output SPSS hasil uji heteroskedastisitas melalui uji glejser di atas menunjukkan bahwa nilai Sig variabel Tingkat Pendidikan, 
Pengalaman Kerja, dan Independensi Auditor berada diatas 0,05 atau lebih besar dari 0,05. Sedangkan nilai Sig variabel Etika Profesi berada dibawah 0,05.

\section{Uji Autokorelasi}

Tabel DW unuk df $=56$ sampai 59

\begin{tabular}{|c|c|c|c|c|c|c|c|c|}
\hline \multirow{2}{*}{$\mathbf{n}$} & \multicolumn{2}{|c|}{$\mathbf{k = 1}$} & \multicolumn{2}{c|}{$\mathbf{k = 2}$} & \multicolumn{2}{c|}{$\mathbf{k = 3}$} & \multicolumn{2}{c|}{$\mathbf{k = 4}$} \\
\cline { 2 - 9 } & $\mathbf{d L}$ & $\mathbf{d U}$ & $\mathbf{d L}$ & $\mathbf{d U}$ & $\mathbf{d L}$ & $\mathbf{d U}$ & $\mathbf{d L}$ & $\mathbf{d U}$ \\
\hline $\mathbf{5 6}$ & 1.5320 & 1.6045 & 1.4954 & 1.6430 & 1.4581 & 1.6830 & 1.4201 & 1.7246 \\
\hline $\mathbf{5 7}$ & 1.5363 & 1.6075 & 1.5004 & 1.6452 & 1.4637 & 1.6845 & 1.4264 & 1.7253 \\
\hline $\mathbf{5 8}$ & 1.5405 & 1.6105 & 1.5052 & 1.6475 & 1.4692 & 1.6860 & 1.4325 & 1.7259 \\
\hline $\mathbf{5 9}$ & 1.5446 & 1.6134 & 1.5099 & 1.6497 & 1.4745 & 1.6075 & 1,4385 & 1.7266 \\
\hline
\end{tabular}

Berdasarkan Tabel DW di atas, didapatkan nilai dL sebesar 1.4325 dan dU sebesar 1.7259. Untuk mengetahui apakah terdapat autokorelasi dalam model regresi dapat dilihat pada Tabel sebagai berikut:

Model Summary

\begin{tabular}{|l|r|r|r|r|r|}
\hline Model & $\mathrm{R}$ & $\mathrm{R}$ Square & $\begin{array}{c}\text { Adjusted R } \\
\text { Square }\end{array}$ & $\begin{array}{c}\text { Std. Error of } \\
\text { the Estimate }\end{array}$ & $\begin{array}{c}\text { Durbin- } \\
\text { Watson }\end{array}$ \\
\hline 1 &, $817^{\mathrm{a}}$ &, 668 &, 643 & 1,87508 & 1,949 \\
\hline
\end{tabular}

a. Predictors: (Constant), Independensi Auditor, Pengalaman Kerja,

Tingkat Pendidikan, Etika Profesi

b. Dependent Variable: Kualitas Audit

er: Data Output SPSS 21.0

Dari Tabel output SPSS hasil uji autokorelasi di dapat nilai DW yang dihasilkan dari model regresi adalah 1,949. Artinya nilai DW 1,949 (d) lebih besar dari 1,7259 (dU) dan kurang dari 2,2741 (4-dU) atau dU $<\mathrm{d}<4-\mathrm{dU}$, maka dapat disimpulkan bahwa Ho tidak ditolak dan menyatakan tidak ada autokorelasi positif atau negatif atau dapat disimpulkan tidak terdapat autokorelasi.

\subsubsection{Analisis Korelasi}

Untuk menganalisis korelasi antara variabel Tingkat Pendidikan, Pengalaman Kerja, Etika Profesi dan Independensi Auditor terhadap Kualitas Audit dapat dilihat dari hasil SPSS pada tabel 4.22 sebagai berikut : 
Tabel 4.22

Hasil Uji Analisis Korelasi

Correlations

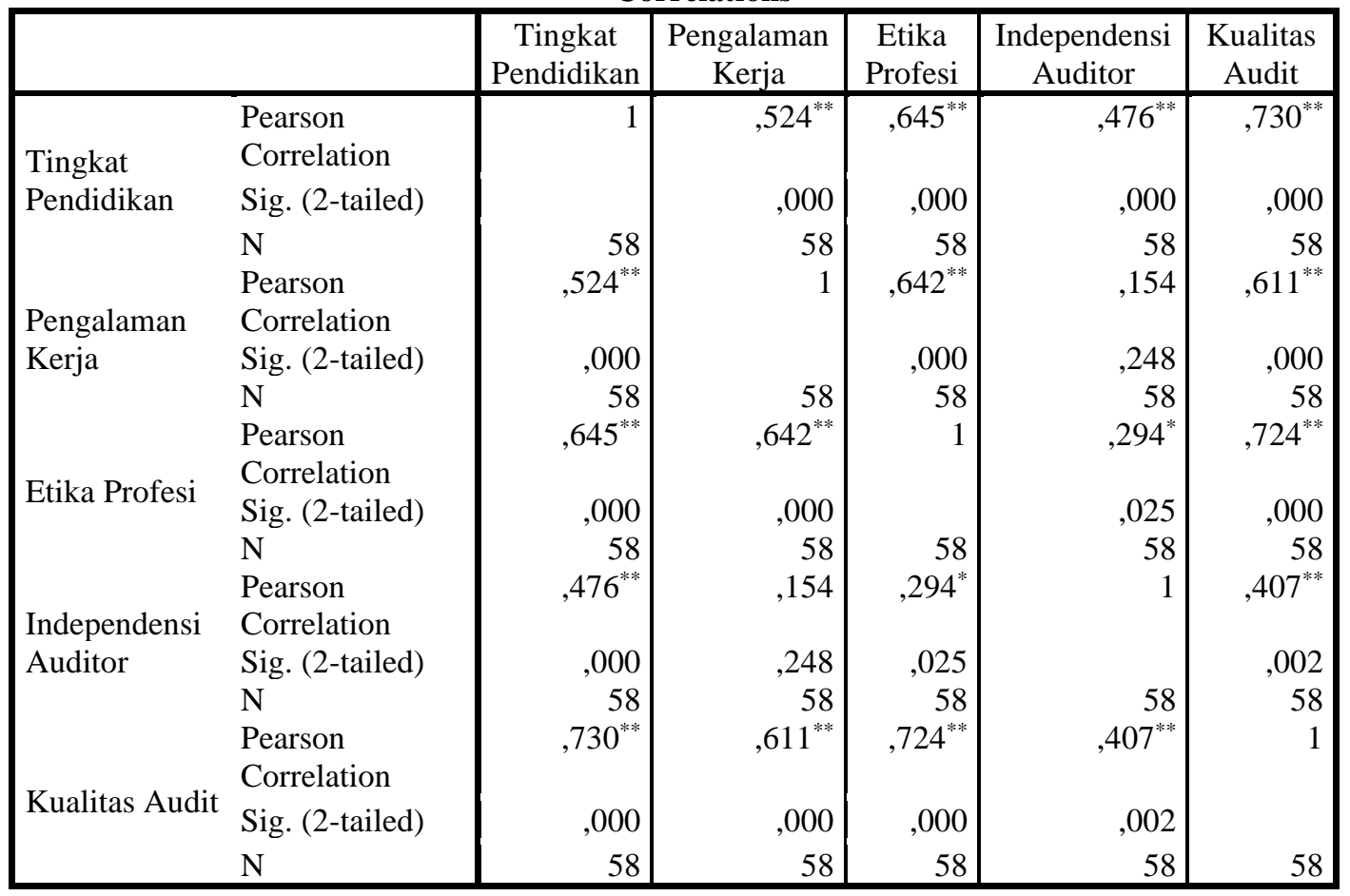

**. Correlation is significant at the 0.01 level (2-tailed).

*. Correlation is significant at the 0.05 level (2-tailed).

Sumber: Data Output SPSS 21.0

Uji F (Uji Simultan)

Hasil Uji F (Simultan)

ANOVA ${ }^{\mathrm{a}}$

\begin{tabular}{|c|c|c|c|c|c|c|}
\hline \multicolumn{2}{|c|}{ Model } & $\begin{array}{l}\text { Sum of } \\
\text { Squares }\end{array}$ & Df & $\begin{array}{c}\text { Mean } \\
\text { Square }\end{array}$ & $\mathrm{F}$ & Sig. \\
\hline \multirow{3}{*}{1} & Regression & 374,765 & 4 & 93,691 & 26,648 &, $000^{\mathrm{b}}$ \\
\hline & Residual & 186,343 & 53 & 3,516 & & \\
\hline & Total & 561,108 & 57 & & & \\
\hline
\end{tabular}

a. Dependent Variable: Kualitas Audit

b. Predictors: (Constant), Independensi Auditor, Pengalaman Kerja, Tingkat Pendidikan, Etika Profesi

Sumber: Data Output SPSS 21.0

Berdasarkan tabel 4.24 di atas menunjukan bahwa $F_{\text {hitung }}$ sebesar 26,648 dimana $F_{\text {hitung }}$ bernilai lebih besar dari $F_{\text {tabel }}$ sebesar $2,55(26,648>2,55)$ dan

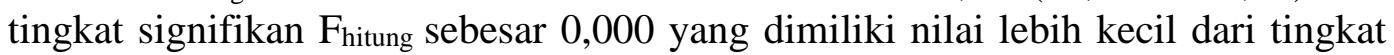
signifikan $F_{\text {tabel }}$ sebesar $0,05(0,000<0,05)$. Dengan demikian berarti Ho ditolak dan Ha diterima sehingga dapat disimpulkan bahwa Tingkat Pendidikan, Pengalaman Kerja, Etika Profesi, dan Independensi Auditor, berpengaruh secara bersama-sama (simultan) terhadap Kualitas Audit. 


\section{Uji t (Uji Parsial)}

\section{Coefficients $^{\text {a }}$}

\begin{tabular}{|c|c|c|c|c|c|}
\hline \multirow[t]{2}{*}{ Model } & \multicolumn{2}{|c|}{$\begin{array}{l}\text { Unstandardized } \\
\text { Coefficients }\end{array}$} & \multirow{2}{*}{$\begin{array}{c}\text { Standardized } \\
\text { Coefficients }\end{array}$} & \multirow[t]{2}{*}{$\mathrm{T}$} & \multirow[t]{2}{*}{ Sig. } \\
\hline & B & Std. Error & & & \\
\hline (Constant) & 1,031 & 1,631 & & ,633 &, 530 \\
\hline Tingkat Pendidikan & ,434 &, 137 & ,364 & 3,155 & ,003 \\
\hline Pengalaman Kerja & ,275 &, 156 &, 187 & 1,763 & ,084 \\
\hline Etika Profesi & ,203 & ,071 & ,338 & 2,880 & ,006 \\
\hline Independensi Auditor & 101 &, 087 &, 106 & 1,163 & 250 \\
\hline
\end{tabular}

a. Dependent Variable: Kualitas Audit

\section{Sumber: Data Output SPSS 21.0}

Berdasarkan Tabel di atas, maka dapat dijelaskan mengenai pengaruh secara parsial

\section{Hasil Koefisien Determinasi $\left(\mathbf{R}^{2}\right)$}

Model

Summary ${ }^{\mathbf{b}}$

\begin{tabular}{|l|r|r|r|r|r|}
\hline $\begin{array}{l}\text { Mode } \\
1\end{array}$ & $\mathrm{R}$ & $\begin{array}{c}\mathrm{R} \\
\text { Square }\end{array}$ & $\begin{array}{c}\text { Adjusted R } \\
\text { Square }\end{array}$ & $\begin{array}{c}\text { Std. Error of } \\
\text { the Estimate }\end{array}$ & $\begin{array}{c}\text { Durbin- } \\
\text { Watson }\end{array}$ \\
\hline 1 &, $817^{\mathrm{a}}$ &, 668 &, 643 & 1,87508 & 1,949 \\
\hline
\end{tabular}

a. Predictors: (Constant), Independensi Auditor, Pengalaman Kerja, Tingkat Pendidikan, Etika Profesi

b. Dependent Variable: Kualitas Audit

B

Berdasarkan Tabel di atas, diperoleh bahwa nilai koefisien determinasi (Adjusted $\mathrm{R}$ Square) sebesar 0,643 ini menunjukkan bahwa besar pengaruh dari variabel tingkat pendidikan, pengalaman kerja, etika profesi, dan independensi auditor terhadap variabel kualitas audit adalah 64,3\%. Sedangkan sisanya 35,7\% (100\%$64,3 \%$ ) dapat dipengaruhi oleh variabel-variabel lain yang tidak termasuk dalam penelitian ini.

\section{Analisis Regresi Linear Berganda}

Dengan menggunakan Statistic Package for the Social Science (SPSS) Versi 21.0 dapat diperoleh hasil koefisien regresi sebagai berikut:

\section{Hasil Uji Analisis Regresi Linear Berganda}

\section{Coefficients ${ }^{\mathrm{a}}$}

\begin{tabular}{|c|c|c|c|c|c|c|}
\hline \multirow{2}{*}{\multicolumn{2}{|c|}{ Model }} & \multicolumn{2}{|c|}{$\begin{array}{c}\text { Unstandardized } \\
\text { Coefficients }\end{array}$} & \multirow{2}{*}{$\begin{array}{c}\begin{array}{c}\text { Standardized } \\
\text { Coefficients }\end{array} \\
\text { Beta }\end{array}$} & \multirow[t]{2}{*}{$\mathrm{t}$} & \multirow[t]{2}{*}{ Sig. } \\
\hline & & B & Std. Error & & & \\
\hline \multirow{5}{*}{1} & (Constant) & 1,031 & 1,631 & & ,633 &, 530 \\
\hline & Tingkat Pendidikan & ,434 & , 137 & ,364 & 3,155 & ,003 \\
\hline & Pengalaman Kerja & ,275 & , 156 & , 187 & 1,763 & 084 \\
\hline & Etika Profesi & ,203 &, 071 & ,338 & 2,880 & ,006 \\
\hline & Independensi Auditor & ,101 & ,087 & , 106 & 1,163 &, 250 \\
\hline
\end{tabular}

a. Dependent Variable: Kualitas Audit 


\section{DAFTAR PUSTAKA}

Agoes, Sukrisno. 2016. Auditing Petunjuk Praktis Pemeriksaan Akuntan oleh Akuntan Publik Edisi 4. Jakarta: Salemba Empat.

Agoes, Sukrisno dan I Cenik Ardana 2016. Etika Bisnis dan Profesi: Tantangan Membangun Manusia Seutuhnya. Jakarta: Salemba Empat.

Arens, Alvin A, Rsndsl J. Elder, dan Mark S. Beasley. (2016). Auditing \& Jasa Assurance Edisi Kelimabelas Jilid 1. Jakarta: Erlangga.

Ghozali, Imam. 2013. Aplikasi Analisis Multivariet Dengan Program IBM SPSS 21 Edisi 7. Semarang: Undip.

Harahap, Sofyan S. 2017. Etika Bisnis dalam Perspektif Islam. Jakarta: Salemba Empat.

Mulyadi. 2014. Auditing Edisi 6. Jakarta: Salemba Empat.

Qudratullah, Mohammad Farhan. 2017. Analisis Regresi Terapan. Yogyakarta: Andi.

Sekaran, Uma. 2017. Metodologi Penelitian Untuk Bisnis edisi 4. Jakarta: Salemba Empat.

Sugiyono. 2017. Metode Penelitian Kuantitatif, Kualitatif dan R\&D. Bandung: Alfabeta.

Sujawerni, V. Wiratna. 20157SPSS Untuk Penelitian. Yogyakarta: Pustaka Baru Press.

Tandiontong, Mathius. 2018. Kualitas Audit dan Pengukurannya. Bandung: Alfabeta.

Trihendradi, Cornelius. 2018. Step By Step IBM SPSS 21 : Analisis Data Statistik. Yogyakarta: CV. Andi Offset.

Dharmawan, Nyoman Ari Surya. 2016. Pengaruh Tingkat Pendidikan Dan Pengalaman Pemeriksa Terhadap Kualitas Hasil Pemeriksaan (Studi Empiris Pada Kantor Inspektorat Kabupaten Klungkung Dan Karangasem). Jurnal Ilmiah Akuntansi dan Humanika Vol 4, No 1, ISSN: 20893310. Universitas Pendidikan Ganesha.

Fachruddin, Wan dan Sri Handayani. 2017. Pengaruh Fee Audit, Pengalaman Kerja, Dan Independensi Auditor Terhadap Kualitas Audit Pada Kantor Akuntan Publik Di Kota Medan. Jurnal Akuntansi dan Bisnis Vol. 3 No. 2. ISSN (online): 2503-0337. Universitas Muhammadiyah Sumatera Utara.

Fermana, Amelia Bettry. 2017. Pengaruh Keahlian, Independensi Dan Kemahiran Profesional Terhadap Kualitas Hasil Pemeriksaan Dengan Pengalaman Kerja Sebagai Variabel Moderating (Studi Empiris Pada Inspektorat Kota Pekanbaru Dan Kota Dumai). Jurnal Fakultas Ekonomi Vol 2 No 2. Universitas Riau.

Futri, Putu Septiani dan Gede Juliarsa. 2017. Pengaruh Independensi, Profesionalisme, Tingkat Pendidikan, Etika Profesi, Pengalaman, dan Kepuasan Kerja Auditor Terhadap Kualitas Audit Kantor Akuntan Publik Di Bali. E-Jurnal Akuntansi Universitas Udayana 7.2: 444 - 461. ISSN: 2302-8556.

Gimardien, Zhella Rachma. 2017. Pengaruh Kompetensi, Independensi, Profesionalisme, Tingkat Pendidikan, dan Pengalaman Terhadap Kualitas Audit (Studi Empiris pada Kantor Akuntan Publik di Jawa Tengah dan 
Daerah Istimewa Yogjakarta). Skripsi. Universitas Muhammadiyah Surakarta.

Hasbullah, Ni Luh Gede Erni Sulindawati, dan Nyoman Trisna Herawati. 2017.

Pengaruh Keahlian Audit, Kompleksitas Tugas, Dan Etika Profesi

Terhadap Kualitas Audit (Studi Pada Inspektorat Pemerintah Kota Denpasar Dan Inspektorat Pemerintah Kabupaten Gianyar). e-Journal S1

Ak Jurusan Akuntansi S1 Volume 2 No: 1. Universitas Pendidikan Ganesha.

Laksmi Dewi, GAA. 2016. Pengaruh Tingkat Pendidikan, Pelatihan Kerja, Pengalaman Kerja, dan Profesionalisme Petugas Pemeriksa Pajak Pada Penyelesaian Pemeriksaan Pajak di Kantor Pelayanan Pajak Pratama seBali. Skripsi. Jurusan Akuntansi Fakultas Ekonomi Universitas Udayana, Denpasar.

Ningtyas, Widya Arum dan Mochammad Abdul Aris. 2016. Independensi, Kompetensi, Pengalaman Kerja, Dan Due Professional Care: Pengaruhnya Terhadap Kualitas Audit Yang Dimoderasi Dengan Etika Profesi (Studi Empiris Pada Kantor Akuntan Publik Se-Jawa Tengah Dan DIY). Jurnal Akuntansi Fakutas Ekonomi dan Bisnis. Universitas Muhammadiyah Surakarta.

Prasetyo, Eko Budi dan I Made Karya Utama. 2016, Pengaruh Independensi, Etika Profesi, Pengalaman Kerja, dan Tingkat Pendidikan Auditor Pada Kualitas Audit. E-Jurnal Akuntansi Universitas Udayana. 11.1: 115-129. ISSN : $2302-8556$.

Rahayu, Titin dan Bambang Suryono. 2016. Pengaruh Independensi Auditor, Etika Auditor, dan Pengalaman Auditor Terhadap Kualitas Audit. Jurnal Ilmu dan Riset Akuntansi volume 5 Nomer 4. ISSN : 2460-0585. Sekolah Tinggi Ilmu Ekonomi Indonesia (STIESIA) Surabaya.

Singgih, Elisha Mulyani dan Icuk Rangga Bawono, 2016, Pengaruh Independensi, Pengalaman, Due Professional Care Dan Akuntabilitas Terhadap Kualitas Audit (Studi Pada Auditor Di KAP "Big Four" Di Indonesia), Simposium Nasional Akuntansi XIII Purwokerto 2010, hal. 2-21. Universitas Jenderal Soedirman Purwokerto.

Sari, Nungky Nurmalita. 2016Pengaruh Pengalaman Kerja, Independensi, Objektivitas, Integritas, Kompetensi dan Etika Terhadap Kualitas Audit. Skripsi Akuntansi Universitas Diponegoro.

Sari, Ni Putu Piorina Fortuna dan I Wayan Ramantha. 2016. Pengaruh Sikap Skeptisme, Pengalaman Audit, Kompetensi, dan Independensi Auditor Pada Kualitas Audit. E-Jurnal Akuntansi Universitas Udayana 11.2: 470-482. ISSN: 2302-8556.

Susilawati, dan Maya R Atmawinata. 2016. Pengaruh Profesionalisme Dan Independensi Auditor Internal Terhadap Kualitas Audit: Studi Pada Inspektorat Propinsi Jawa Barat. Jurnal Ekonomi STIE STEMBI 13(2).

Susmiyanti. 2016. Pengaruh Fee audit, Time Budget Pressure, dan Kompleksitas Tugas terhadap Kualitas Audit dengan Pengalaman Auditor sebagai Variabel Moderating (Studi empiris pada Kantor Akuntan Publik di Yogyakarta). Skripsi, Fakultas Ekonomi Universitas Negeri Yogyakarta.

Wahyuni, Rizki. 2017. Pengaruh Independensi, Kompetensi, Profesionalisme, Dan Sensitivitas Etika Profesi Terhadap Kualitas Audit (Studi Kasus Pada 
BPK Ri Perwakilan Provinsi Sulawesi Selatan). Skripsi, Jurusan Akuntansi Fakultas Ekonomi Dan Bisnis pada Universitas Hasanuddin Makassar.

Peraturan Menteri Keuangan No. 25 tahun 2014 tentang Akuntansi Beregister Negara

Undang-Undang No. 20 Tahun 2003 tentang Sistem Pendidikan Nasional 